\title{
Analytical and Numerical Study on the Performance of Supersonic Ejector at Different Operating Conditions and Working Fluids
}

\author{
S. K. Yadav ${ }^{1}$, K. M. Pandey ${ }^{1 \dagger}$ and R. Gupta ${ }^{2}$ \\ ${ }^{1}$ Department of Mechanical Engineering, National Institute of Technology, Silchar, Assam-788010, India \\ ${ }^{2}$ Department of Mechanical Engineering, National Institute of Technology, Mizoram, India \\ †Corresponding Author Email: kmpandey2001@yahoo.com
}

(Received December, 17 2020; accepted May 18, 2021)

\begin{abstract}
The computation of ejector geometry for a given fluid is essential and plays a crucial role in creating an ejector profile and performance analysis. The current paper discusses the constant rate of momentum change (CRMC) approach using a real gas equation for ejector design. The numerical analysis is carried to validate the analytical geometry and the effect of operating parameters on the entrainment ratio. The variation in entrainment ratio for the different working fluids has also been studied on the geometry computed for water-vapour. It is observed that the entrainment ratio of the ejector significantly varies with the change in operating conditions and working fluids. The numerically predicted entrainment ratio is $\sim 0.354$ compared to the on-design entrainment ratio 0.4 for water vapor, while the predicted entrainment ratio for other working fluids is $\sim 0.319, \sim 0.314$, and $\sim 0.36$ for air, $\mathrm{N}_{2}$, and $\mathrm{CO}_{2}$, respectively.
\end{abstract}

Keywords: Ejector; CRMC; Jet-pump; Entrainment Ratio; Working fluids.

\section{NOMENCLATURE}

$\begin{array}{cl}\mathrm{C} & \text { velocity } \\ \rho & \text { density } \\ \mathrm{T} & \text { temperature } \\ \mathrm{P} & \text { static Pressure } \\ \mathrm{E} & \text { exit } \\ \mathrm{X} & \text { axial distance } \\ \mathrm{w} & \text { molecular weight } \\ \mathrm{a}, \mathrm{b} & \text { constant (Redlich Kwong) } \\ f & \text { Fanning friction factor } \\ \mathrm{r} & \text { radius } \\ \Omega & \text { area } \\ \alpha & \text { CRMC constant } \\ \mathrm{M} & \text { Mach number } \\ \dot{m} . & \text { mass flow rate } \\ \varphi & \text { entrainment ratio }\end{array}$

$\begin{array}{ll}\gamma & \text { specific heat ratio values }=1.324 \\ \mathrm{R} & \text { gas constant (individual) }=461.2 \\ \mathrm{C}_{\mathrm{p}} & \text { specific heat } \\ G_{k} & \text { generation of turbulent kinetic energy } \\ Y_{k}, Y_{\omega} & \text { dissipation of K and } \omega \\ S_{k}, S_{\omega} & \text { source terms } \\ G_{\omega} & \text { generation of dissipation } \\ D_{\omega} & \text { cross diffusion term } \\ \omega & \text { dissipation rate } \\ \mathrm{k} & \text { kinetic energy(turbulent) } \\ \mathrm{Re} & \text { Reynolds number } \\ \mu & \text { viscosity (dynamic) } \\ \mathrm{K} & \text { wall roughness } \\ \propto_{1} \propto_{2} & \text { Sutherland constant }\end{array}$

\section{INTRODUCTION}

In numerous industries, heat energy has been adopted as an impetus force in the required domains of its usage. The system's unutilized low-grade heat energy or energy dissipated could be adapted for co- generation intendment to steer the supersonic ejector systems. Ejector is an economically and environmentally friendly device with low maintenance costs as there are no moving parts. Confederating the flow performance of the primary consigned flow and the flow assertion of the fluids in 


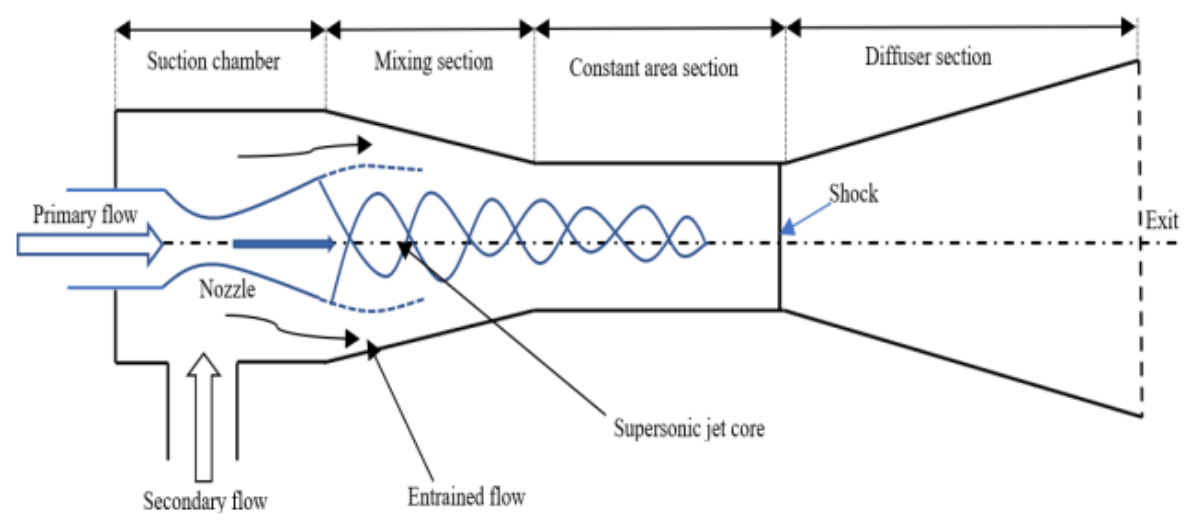

Fig. 1. Ejector system.

the mixing section of the ejector is one of the indispensable prerequisites for designing a highperformance ejector for a specified working fluid. Figure 1 depicts the ejector model developed in the early nineteenth century Keenan and Neumann (1942). The supersonic ejector geometry consists of a supersonic nozzle and mixing segment and a subsonic diffuser segment. The analytical modelling of the ejector system has always been an exigent task for researchers. Keenan and Neumann (1942) proposed two practical solutions to model the supersonic ejectors. The first model was based on constant area mixing (CAM) and the subsequent one, constant pressure mixing (CPM). Both methods have engrossed a lot of interest. But both these proposed design models suffer from low performance. The performance of the ejector is generally defined in terms of entrainment ratio, which is a ratio of secondary mass flow rate to primary mass flow rate. The major source of Irreversibility in both the CAM and CPM ejectors is the occurrence of thermodynamic shock within the constant area part of the diffuser (refer Fig. 1). And this causes mixedflow velocity to decelerate from supersonic to subsonic. The precedent of thermodynamic shock in a conventional ejector is a major prorogation in designing a high-performance, supersonic ejector.

To overcome this, Eames (2002) proposed a onedimensional theory for diffuser design formulated based on the constant rate of momentum change (CRMC). Later Kumar et al. (2013) modified this CRMC one-dimensional gas dynamic theory for all the ejector components with a frictional effect for an ideal gas. The alternate model based on the constant rate of kinetic energy change (CRKEC) with a frictional effect has also been tested by Kumar et al. (2018) for an ideal gas. Both the CRMC and CRKEC model eradicates the constant area section of the CAM and CPM ejector. The variable area mixingdiffuser based on CRMC and CRKEC ejector tranquilizes the loss due to thermodynamic shocks, which were pragmatic in the empirical model of the ejector. Though, the performance of the supersonic ejector is a function of geometrical and operating parameters. Plenty of literature has been proposed to understand the impact, including design approaches
(Seehanam et al. 2007; Kumar et al. 2019), geometrical parameters (Li et al. 2019; Zhu et al. 2009; Wu et al. 2018; Lin et al. 2013), and operating parameters (Huang et al. 1985; Shestopalov et al. 2015; Aidoun and Ouzzane 2004; Vereda et al. 2012) in different fields of applications for various working fluids (Croquer et al. 2017; Cardemil and Colle 2012; Zhu and Jiang 2014) at on/off design conditions. The computational fluid dynamics (CFD) tools play an essential job in ejector design optimization and performance evaluation. Experimental setups are costly and limited to study the number of design and operating parameters. The CFD also helps in flow visualization and shock prediction in supersonic ejector studies (Gagan et al 2014; Su and Agarwal 2016; Ramesh and Sekhar 2017; Ruangtrakoon et al. 2013).

The CRMC approach with a frictional effect for real fluids is missing in the available literature. The present study modified the available CRMC approach for ejector design from ideal gas to real gas. The developed analytical 1D gas dynamic model has been exercised to figure out a geometrical profile and flow behavior. Further, The CFD tool ANSYSFLUENT-14.0 has been harnessed to analyze the computed ejector geometry for the on-design operating condition and working fluid. The ejector performance has also been studied other than ondesign working fluids (water-vapor) to predict the versatility of geometry.

\section{ANALYTICAL SOLUTION}

The current work taken into consideration the axissymmetric ejector only. This section presents the 1D compressible flow theory based on CRMC with a frictional effect for the real fluid. The design methodology is carried based on adiabatic steady state, steady flow system of equations. The basic equations and their differential forms (1)-(5) utilized are mentioned below.

Mach number

$M=\frac{C^{2}}{\gamma R T}: \frac{\delta M}{M}+\frac{\delta C}{C}+\frac{\delta T}{T}$ 
S. K. Yadav al. / JAFM, Vol. 14, No. 6, pp. 1705-1716, 2021.

Redlich-Kwong real-gas equation of state

$P=\frac{R T}{\left(V_{m}-b\right)}-\frac{a}{V_{m}\left(V_{m}+b\right) T^{0.5}}: \quad \delta P=S \delta T+Z \delta \rho$

where;

$S=\frac{\rho R}{(w-\rho b)}+\frac{a \cdot \rho^{2}}{2 w(w+\rho b) T^{1.5}}$

$Z=\frac{R T w}{(w-\rho b)^{2}}-\frac{\left(a \rho 2 w+a \rho^{2} b\right)}{\left(w^{3}+\rho^{2} b^{2} w+2 w^{2} \rho b\right)}$

Conservation of Mass

$\dot{m}=\rho \Omega C: \frac{\delta \rho}{\rho}+\frac{\delta \Omega}{\Omega}+\frac{\delta C}{C}$

Energy conservation

$T_{o}=T+\frac{C^{2}}{2 C_{p}}: \delta T+\frac{C \delta C}{C_{p}}=0$

Conservation of momentum

$$
\frac{\delta P}{P}+C^{2} 4 f \frac{\delta x}{D_{h}}+\gamma M^{2} \frac{\delta C}{C}=0
$$

The following assumptions have been made to the development of CRMC ejector using 1-D gas dynamic theory:

The Redlich Kwong real fluid equation of state has been considered.

The desired entrainment ratio $(\varphi)$ is known.

The secondary flow velocity at the inlet of the entrainment region is specified.

Steady-state, one-dimensional flow is considered.

Adiabatic flow is specified.

Water vapour has been considered as a working fluid for both streams.

Constant static pressure is considered inside the mixing area to compute the mixing region.

Equation 6 is used as the baseline equations for the design of mixing and diffuser sections.

$\frac{\delta \dot{\mathrm{M}}}{\delta x}=\dot{\mathrm{m}}_{\mathrm{p}}(1+\varphi) \frac{\delta c}{\delta x}=\alpha$

Where $\alpha\left(\mathrm{kg} / \mathrm{s}^{2}\right)$ is known as the CRMC constant, it has been varied to obtain a different profile of the mixing and diffuser sections for a given design condition.

For the selected value of $\alpha$, the velocity gradients were computed using the below equations.
The following set of equations gives the progressive development in profiles of ejector geometry and flow parameters of interest.

Progressive development in the local cross-sectional area at the $i^{\text {th }}$ location from $J-J^{\prime}$ :

$\frac{\delta \Omega}{\Omega_{j, x}}=\frac{\gamma}{2} M_{j, x}^{2} \frac{P_{j, x}}{\rho_{j, x} Z_{j, x}} \frac{4 f_{J, x} \delta x}{D_{h_{j, x}}}+$

$\frac{1}{\rho_{j, x} Z_{j, x}}\left[\gamma M_{j, x}^{2} P_{j, x}-M_{j, x}^{2}(\gamma-1) T_{j, x}-\right.$

$\left.\rho_{j, x} Z_{j, x}\right] \frac{\alpha_{d} \delta x}{m_{p}(1+\varphi) C_{j, x}}$

Progressive development in the local pressure at $i^{\text {th }}$ location from $J-J^{\prime}$ :

$\delta P=\left[S_{j, x} M_{j, x}^{2}(1-\gamma) T_{j, x}-\rho_{j, x} Z_{j, x}\right] \frac{\alpha_{d} \delta x}{m_{p}(1+\varphi) C_{j, x}}-$

$\rho_{j, x} Z_{j, x} \frac{\delta \Omega}{\Omega_{j, x}}$

Progressive development in the local temperature at $i^{\text {th }}$ location from $J-J^{\prime}$ :

$\frac{\delta T}{T_{j, x}}=\left[-(\gamma-1) M_{j, x}^{2}\right] \frac{\alpha_{m} \delta x}{m_{p}(1+\varphi) C_{j, x}}$

Progressive development in the local Mach number at $i^{\text {th }}$ location from $J-J^{\prime}$ :

$\frac{\delta M}{M_{j, x}}=\left[1+\frac{(\gamma-1)}{2} M_{j, x}^{2}\right] \frac{\alpha_{m} \delta x}{m_{p}(1+\varphi) C_{j, x}}$

Specifically, for the mixing section's computation using the 1-D gas dynamic theory, the constant pressure $(\delta P=0)$ mixing hypothesis has been considered (Eames 2002). Therefore, the progressive development in the local cross-sectional area at the $i^{\text {th }}$ location from $J-J^{\prime}$ will be as given in Eq. (12):

$\frac{\delta \Omega}{\Omega_{j, x}}=\frac{1}{\rho_{j, x} Z_{j, x}}$

$\left[S_{j, x} M_{j, x}^{2}(\gamma-1) T_{j, x}+\rho_{j, x} Z_{j, x}\right] \frac{2 f_{J, x} \delta x}{D_{h_{j, x}}}$

All the local parameters viz. area, pressure, temperature, and Mach number were calculated at each $\delta x=0.5 \mathrm{~mm}$ location from $J-J^{\prime}$ in either direction by adding the corresponding progressive development in local parameters. The total pressure and total temperature are also calculated at the next $i^{\text {th }}$ location using the below Eqs. (13)-(14).

$\frac{P_{0, j, x}}{P_{j, x}}=\left[1+\frac{(\gamma-1)}{2} M_{j, x}^{2}\right]^{(\gamma /(\gamma-1))}$

$\frac{T_{0, j, x}}{T_{j, x}}=\left[1+\frac{(\gamma-1)}{2} M_{j, x}^{2}\right]$ 


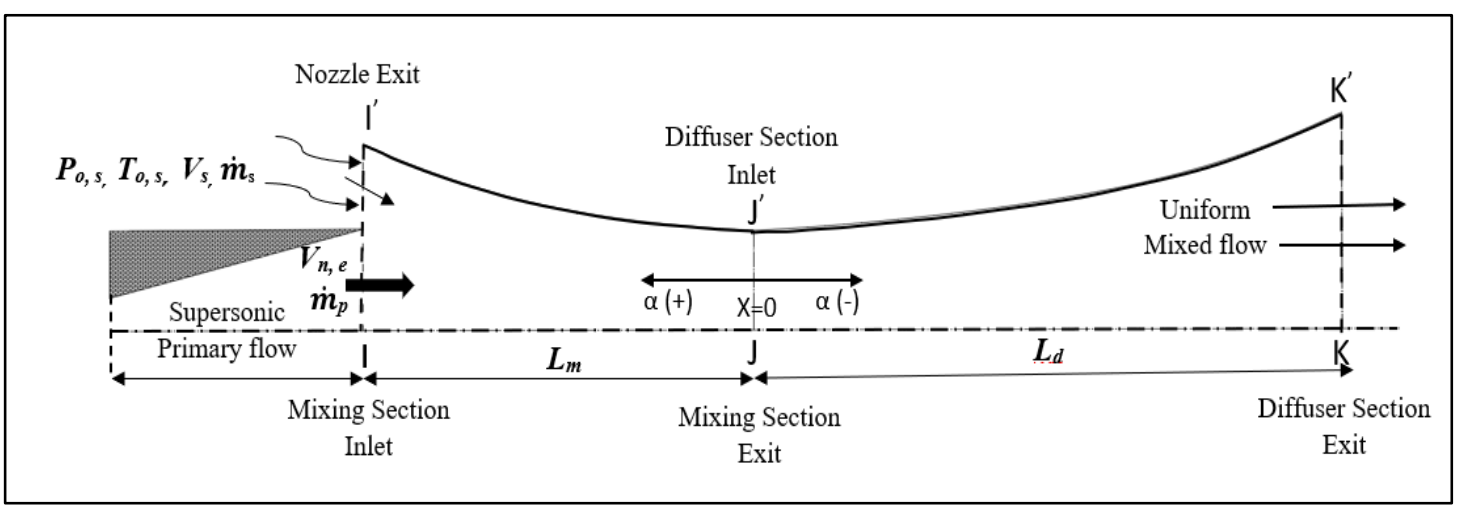

Fig. 2. Discrete modelling of ejector.

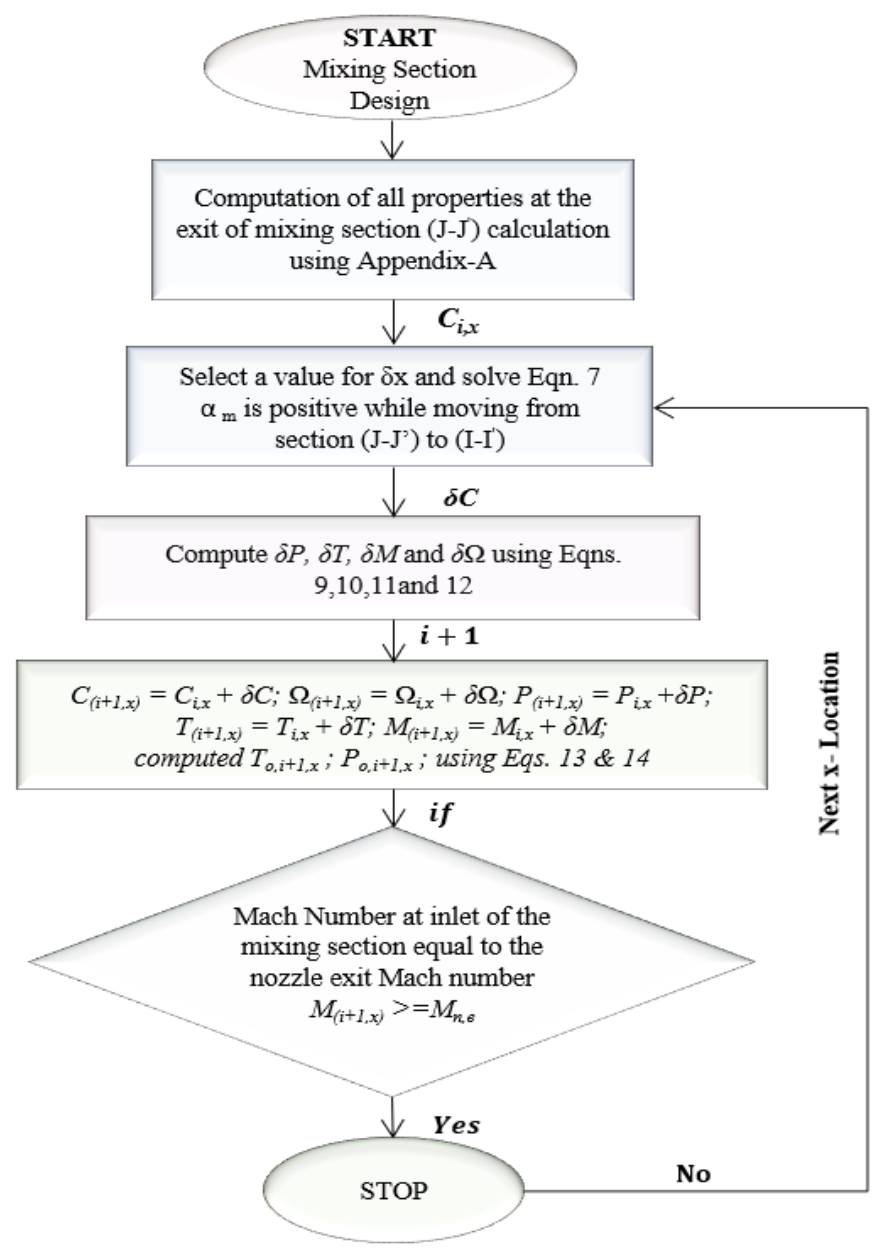

Fig. 3. Mixing section design flow chart.

The primary flow nozzle in the present ejector study has been designed depending on the CRMC theory (Yadav et al. 2020) demonstrated for variable area nozzle. The computation of mixing and diffuser sections starts by calculating thermodynamic equilibrium properties at the end of the mixing section. This calculation was carried based on the assumption of complete mixing theory at the end of the mixing section $\left(J-J^{\prime}\right)$ [refer Appendix A]. After that, the change in geometry (radius) and corresponding Mach number, local pressure, and temperature distributions may be computed along the axial direction (in either direction), moving away from section $\left(J-J^{\prime}\right)$ [refer Fig. 2]. The flow chart for the geometrical computation coordinates and flow properties of mixing and diffuser sections are shown in Fig. 3 and Fig. 4, individually. Where $i$ is the current location and $i+1$ is the location at $\delta x=0.5 \mathrm{~mm}$. 


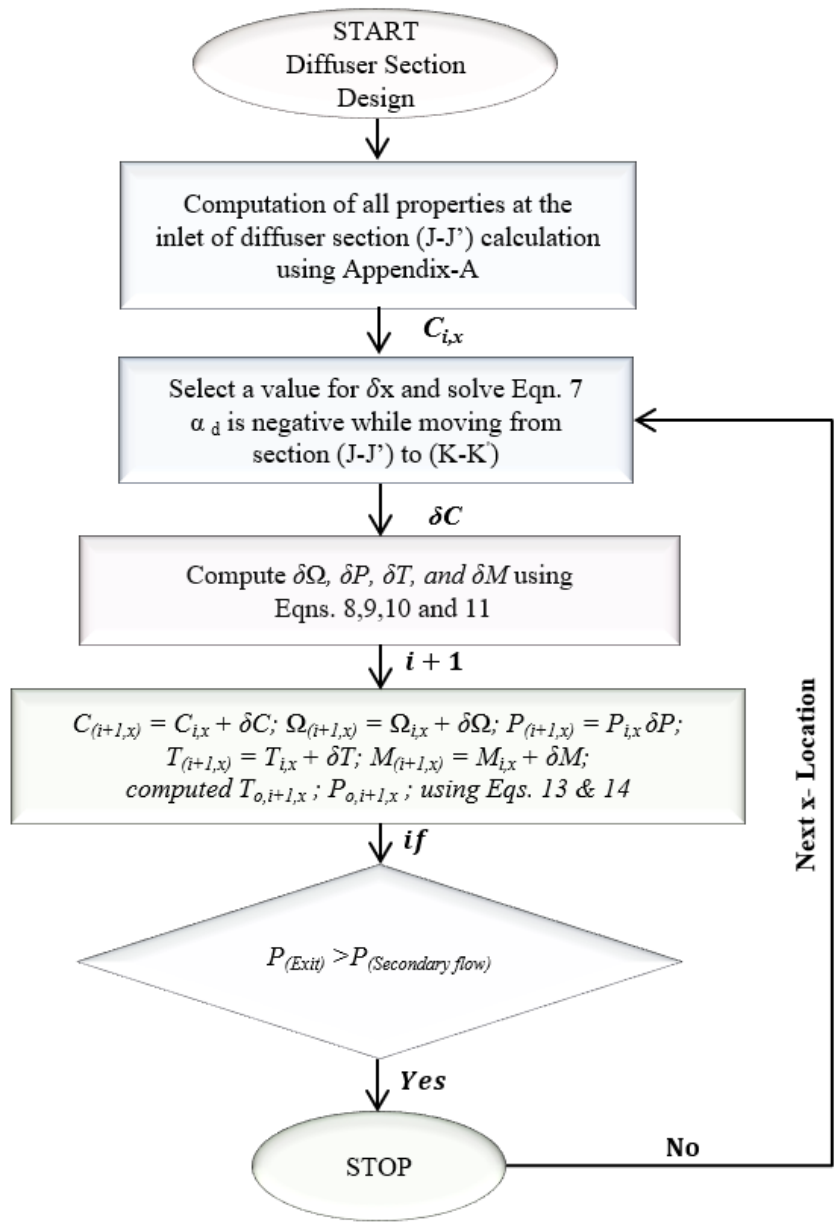

Fig. 4. Diffuser section design flow chart.

The presented design data in Table 1 were utilized in geometry generation and CFD simulation, which can be beneficial for low-grade energy-driven refrigeration applications.

Table 1 Design conditions applied for the ejector.

\begin{tabular}{|l|c|c|c|}
\hline Parameters & Value & Unit & Symbol \\
\hline $\begin{array}{l}\text { Primary flow total } \\
\text { pressure }\end{array}$ & 2.2 & $\mathrm{bar}$ & $\mathrm{P}_{\mathrm{o}, \mathrm{p}}$ \\
\hline $\begin{array}{l}\text { Primary flow total } \\
\text { temperature }\end{array}$ & 392 & $\mathrm{~K}$ & $\mathrm{~T}_{\mathrm{o}, \mathrm{p}}$ \\
\hline $\begin{array}{l}\text { Secondary flow } \\
\text { total pressure }\end{array}$ & 0.014 & $\mathrm{bar}$ & $\mathrm{P}_{\mathrm{o}, \mathrm{s}}$ \\
\hline $\begin{array}{l}\text { Secondary flow } \\
\text { total temperature }\end{array}$ & 290 & $\mathrm{~K}$ & $\mathrm{~T}_{\mathrm{o}, \mathrm{s}}$ \\
\hline $\begin{array}{l}\text { Primary mass } \\
\text { flow rate }\end{array}$ & 0.001 & $\mathrm{~kg} / \mathrm{s}$ & $\dot{m}_{p}$ \\
\hline Entrainment ratio & 0.40 & - & $\varphi$ \\
\hline $\begin{array}{l}\text { Secondary flow } \\
\text { velocity }\end{array}$ & 50 & $\mathrm{~m} / \mathrm{s}$ & $\mathrm{C}$ \\
\hline Specific heat ratio & 1.324 & - & $\gamma$ \\
\hline Gas Constant & 461.52 & $\mathrm{~J} / \mathrm{kg} \mathrm{K}$ & $\mathrm{R}$ \\
\hline Outflow & 0.003 & $\mathrm{bar}$ & $\mathrm{P}_{\mathrm{e}}$ \\
\hline
\end{tabular}

Working fluid-water vapor
The MATLAB codes were employed based on Euler's method for explicit schemes to get an analytical solution. The progressive development was calculated at each small step, typically at $0.5 \mathrm{~mm}$, and it is rounded off to 3 significant decimal places to achieve computational efficacy.

Figure 5 shows the computed variable area profile of the diffuser and mixing region of a supersonic ejector. The complete dimension of the ejector is presented in Table 2.

A unique profile of mixing and diffuser sections can be obtained for individual values of $\alpha$. So, the value of $\alpha$ must be considered wisely. The $\pm \alpha$ value depends on calculation from to towards upstream or downstream of the flow passage. In the present case, $\alpha$ value is selected $+v e$ for the mixing and -ve for the diffuser while computing from section $\left(J-J^{\prime}\right)$.

The $\pm \alpha$ value of the CRMC constant should satisfy the exit condition of the section being computing without reaching the null value of any properties. Further, the optimal value of $\alpha$ is selected based on the required exit/inlet conditions of flow properties for the given length's geometry (mixing/diffuser section). 


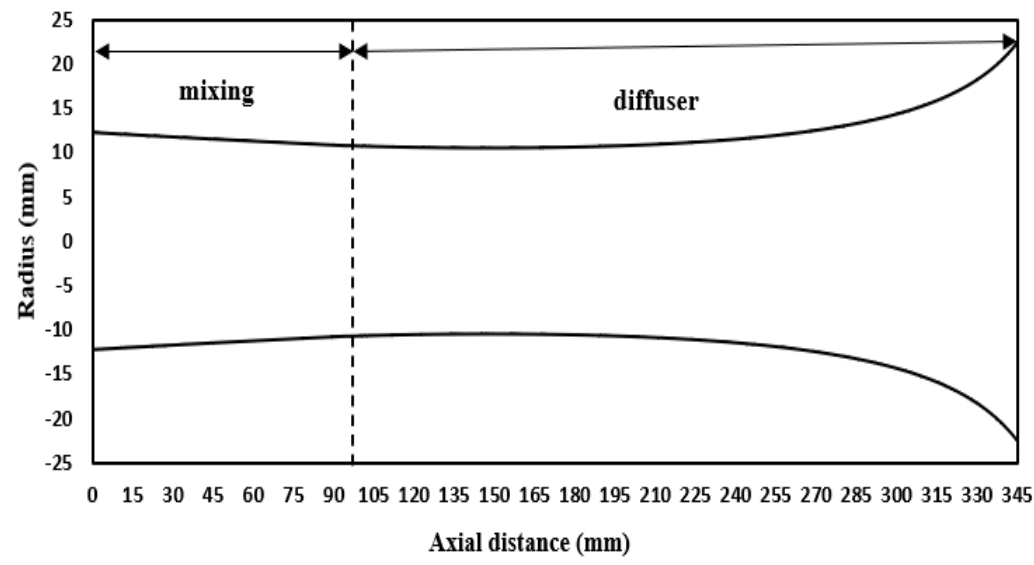

Fig. 5. Variable area profile of the mixing and diffuser section.

Table 2 Dimensional specifications of the mixing and diffuser at key positions.

\begin{tabular}{|c|c|c|c|c|c|}
\hline Geometry $(\mathrm{mm})$ & $\begin{array}{c}\text { CRMC constant, } \\
\alpha\left(\mathrm{kg} / \mathrm{s}^{2}\right)\end{array}$ & Inlet dia. & Exit dia. & Throat & Length \\
\hline mixing & +3.1 & 24.48 & 21.45 & 21.45 & 95 \\
\cline { 1 - 3 } diffuser & -3.5 & 21.45 & 44.8 & & 250 \\
\hline
\end{tabular}

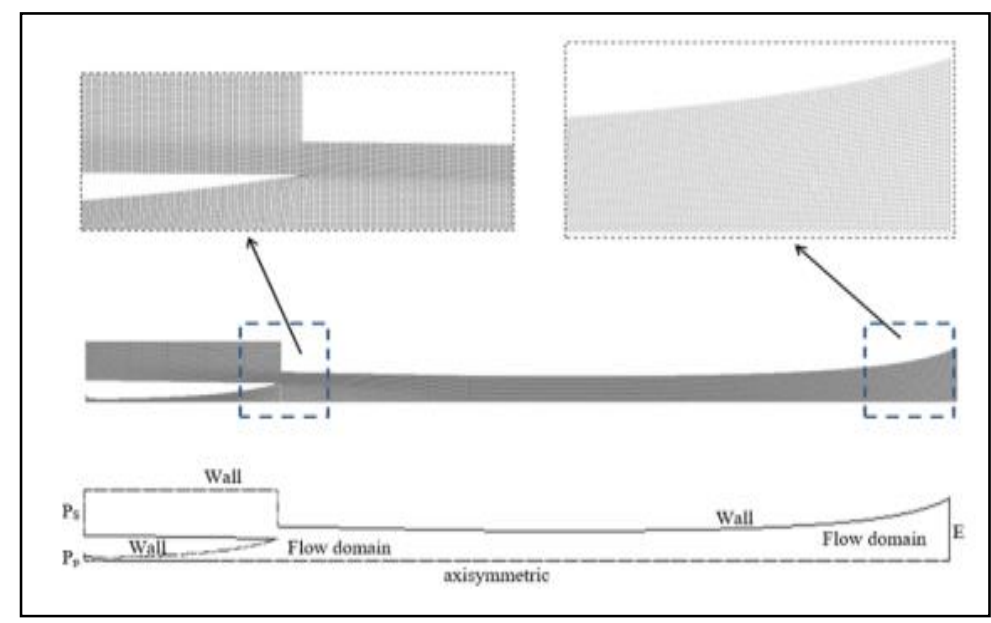

Fig. 6. Computational domain of the ejector.

\section{NUMERICAL SIMULATION}

In the development of ejector design and analysis, the numerical study paves a significant task. To quantify the geometry design, analysis of the work has been done comprehensively by using ANSYSFluent 14.0. For this, a one-dimensional analytical study has been an imperative pre-step. Flow properties like Mach number, pressure, temperature have been evaluated. The universal performance parameter 'entrainment ratio' is computed and substantiated with the results envisaged by the analytical model at the on-design condition. The offdesign ejector characteristics have also been tested to identify the flexibility with operating conditions and working fluids for on-field usage. During the offdesign study, one parameter at a time has been varied, and other parameters have remained fixed.
As in Fig. 6, a 2-D axis-symmetric domain has been developed for the calculated geometrical profile in this study. At first, the grid element number has been set to 36,000 elements in the form of a structured quadrilateral mesh, and subsequently, the mesh independence study has been conducted for the entrainment ratio; the global performance parameter of the ejector. This study escalated grid elements to 56,000 , and the simulated error came out to be less than 5\%. The mesh independence has been ascertained, and the numbers of elements have been restricted to 45,000 all through the design.

And as well as, dense elements have been defined in upper gradient regions such as the mixing/entrainment region. The mesh quality has been assured based on orthogonality and aspect ratio of the generated mesh. The minimum orthogonality and the maximum aspect ratio of the mesh have been 
accomplished to 0.8621 and 4.3287 , respectively. The $\mathrm{Y}+$ value of implemented mesh has been achieved to $\sim 0.7160$.

The Navier-Stokes equation for the 2-D axisymmetric domain with a steady-state turbulence model was solved numerically. The compact cartesian form of governing equations are listed below:

Mass Equation

$\frac{\partial}{\partial x_{i}}\left(\rho u_{j}\right)=0$

Momentum equation

$$
\frac{\partial}{\partial x_{i}}\left(\rho u_{i} u_{j}\right)=-\frac{\partial P}{\partial x_{i}}+\frac{\partial \tau_{j i}}{\partial x_{j}}
$$

Energy equation

$$
\frac{\partial}{\partial x_{i}}\left(u_{i}(\rho E+P)\right)=\vec{\nabla} \cdot\left(\varepsilon_{e f f} \frac{\partial T}{\partial x_{i}}+u_{j}\left(\tau_{j i}\right)\right)
$$

where,

$$
\tau_{i j}=\mu_{e f f}\left(\frac{\partial u_{i}}{\partial x_{j}}+\frac{\partial u_{j}}{\partial x_{i}}\right)-\frac{2}{3} \mu_{e f f} \frac{\partial u_{k}}{\partial x_{k}} \beta_{i j}
$$

The two-equation k- $\omega$ SST (Shear Stress Transport) turbulence model has been utilized for the numerical solution of the supersonic ejector configuration. This model can capture mixing layers and simulate free shear flows in the round and radial jets (Ariafar et al. 2016). The standard wall function is taken under consideration adjacent to the ejector wall.

The governing equations of the turbulence model are as follows (Ariafar et al. 2016).

Turbulence kinetic energy:

$\frac{\partial}{\partial x_{i}}\left(\rho k u_{i}\right)=\frac{\partial}{\partial x_{j}}\left[\left(\mu+\frac{\mu_{t}}{\sigma_{k}}\right) \frac{\partial k}{\partial x_{j}}\right]+G_{k}-Y_{k}+S_{k}$

Specific dissipation rate:

$$
\begin{aligned}
& \frac{\partial}{\partial x_{i}}\left(\rho \omega u_{i}\right)=\frac{\partial}{\partial x_{j}}\left[\left(\mu+\frac{\mu_{t}}{\sigma_{\omega}}\right) \frac{\partial \omega}{\partial x_{j}}\right]+ \\
& G_{\omega}-Y_{\omega}+D_{\omega}+S_{\omega}
\end{aligned}
$$

The model's numerical solution for control volumebased governing equations were made by employing ANSYS-Fluent 14.0 CFD code. The higher-order accuracy has been achieved by discretizing the convection terms of the equations with a secondorder upwind discretization scheme. The obtained algebraic equations after the discretization were solved employing a density-based coupled solver with an implicit method. The Courant-FriedrichsLewy (CFL) criterion was fixed at 5 to maintain the algorithm stability. The pressure boundary condition was employed at the exit and inlet of the primary and secondary flow of the ejector. The applied boundary condition of the ejector is shown in Table 3. The convergence criterion of the solution was set $1 \times 10^{-7}$

\begin{tabular}{|c|c|c|}
\hline Parameters & $\begin{array}{l}\text { Boundary } \\
\text { conditions }\end{array}$ & Values \\
\hline $\begin{array}{c}\text { Primary } \\
\text { Flow Inlet }\end{array}$ & $\begin{array}{l}\text { Primary flow: } \\
\text { Pressure-inlet }\end{array}$ & $\begin{aligned} \mathrm{P}_{\mathrm{o}, \mathrm{p}} & =2.2 \mathrm{bar}, \mathrm{T}_{\mathrm{o}, \mathrm{p}} \\
& =393 \mathrm{~K}\end{aligned}$ \\
\hline $\begin{array}{l}\text { Secondary } \\
\text { Flow Inlet }\end{array}$ & $\begin{array}{c}\text { Secondary } \\
\text { flow: } \\
\text { Pressure-inlet }\end{array}$ & $\begin{array}{c}\mathrm{P}_{\mathrm{o}, \mathrm{s}}=0.0014 \text { bar } \\
\mathrm{T}_{\mathrm{o}, \mathrm{s}}=278 \mathrm{~K}\end{array}$ \\
\hline Exit & $\begin{array}{c}\text { Pressure } \\
\text { outlet }\end{array}$ & $\begin{array}{c}\mathrm{P}_{\mathrm{e}}=0.003 \mathrm{bar} \\
\mathrm{T}_{\mathrm{e}}=358 \mathrm{~K}\end{array}$ \\
\hline Wall & $\begin{array}{c}\text { Standard } \\
\text { adiabatic wall } \\
\text { with no-slip }\end{array}$ & - \\
\hline
\end{tabular}

based on the root mean square with a relaxation factor of 0.3 .

Table 3 Boundary conditions (on-design) for numerical study.

\section{RESULT S AND DISCUSSION}

The numerical study carried out on the ejector, as was considered for the one-dimensional analytical study. For the off-design study, one parameter was varied at a time. Similar to analytical modeling, the nozzle exit position (NXP) was considered at the inlet of the mixing section $(\mathrm{NXP}=0)$. Mach number and static pressure variation are presented inside the ejector, and Mach number contour is employed to visualize the mixing characteristics. The effect of different working fluids and operating conditions on performance of the ejector are also discussed.

\subsection{Flow within the ejector}

The contour of Mach number lines is portrayed in Fig 7. The primary flow accelerates from subsonic at the inlet to supersonic at the exit of the nozzle. At the inlet of the mixing section plane, the primary fluid is supersonic $(\mathrm{M} \approx 4.2)$ and starts interacting with the subsonic secondary flow.

The primary supersonic flow leaves the nozzle at a higher expansion angle. Further, the supersonic level and expansion angles depend on the pressure difference between the entrainment region and the nozzle exit. From Fig 7., the characteristic of the fluid flow inside the entrainment region can be observed along with shock train, supersonic jet core, and shear stress layers. The primary flow streams do not starts interacting with secondary flow streams immediately from the inlet of the section where mixing is done. The annular area that accelerates the secondary fluid to entrain in the entrainment region is named an effective area. The size of the effective area greatly influences the performance of the ejector. The gradual expansion and compression of waves occur in the mixing region of the ejector. While mixing, the fluid exchanges its kinetic energy and momentum. The downstream at high pressure causes the secondary oblique shock waves in series. The numerically predicted centerline Mach number and static pressure are compared with the accompanying values predicted by analytical results, as shown in Figures 8 and 9. The interaction intensity 


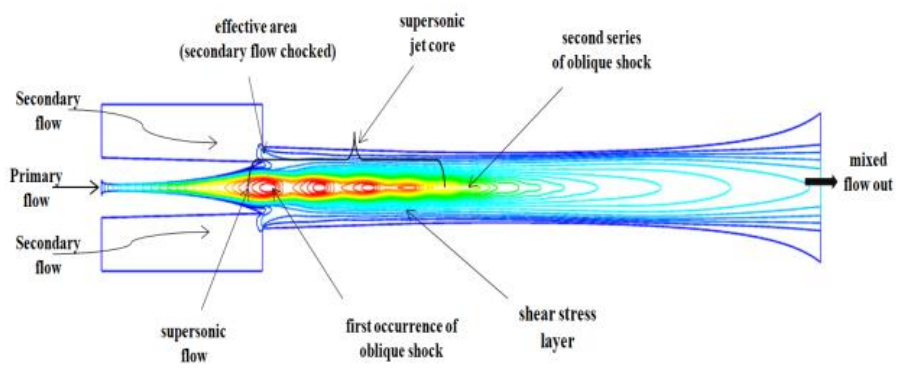

Fig. 7. Contour of Mach number lines.

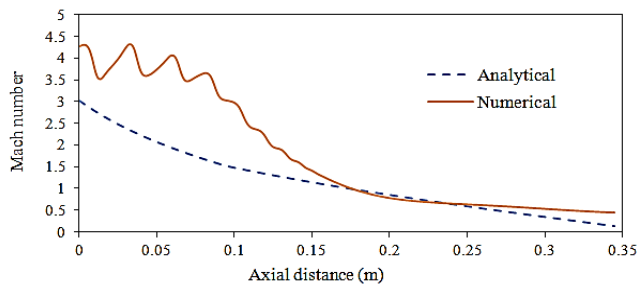

Fig. 8. Mach number variation along the mixing and diffuser sections.

of the primary and secondary fluid in the mixing area can be noticed. Also, despite the association of the supersonic stream and the subsonic secondary stream inside the mixing region, the Mach number comprehensively observed as supersonic. These intense interactions cannot be predicted in analytical results because the one-dimensional CRMC model is essentially an area-averaged formulation. However, the analytical predicted Mach number is less than the numerical centerline Mach number. It could be due to the jet expansion at the nozzle exit.

As expected, computational results show the speedy pulsation of pressure in the mixing region because of the strong interactivity of primary and secondary flow (refer Fig. 9). The average steady pressure pulsations in the mixing province are largely closed to the predicted analytical static pressure, with a 9.7\% variation assumed to be constant in the analytical formulation. The numerically predicted Mach number and pressure variation in the mixing and diffuser sections qualitatively match on-design analytical results.

\subsection{Effect of operating pressure}

The ejector performance has been studied numerically for different operating pressure by varying one operating pressure at a time. The nozzle exit position and operating temperature were kept remain constant as on-design.

The entrainment ratio versus primary flow total pressure is illustrated in Fig. 10. An increment in the primary flow total pressure leads to an increase in mass and momentum of the flow at the nozzle exit. The increase in momentum accelerates the entrainment process in the mixing section. But the rate of increment in secondary mass flow rate to be entrained in the entrainment region is less than that

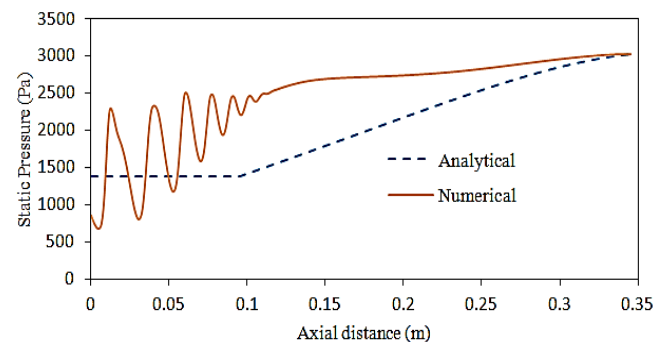

Fig. 9. Static pressure variation along the mixing and diffuser sections.

of the rate at which the primary mass flow rate increases. So, the entrainment ratio initially increases with primary flow total pressure (below on-design primary flow total pressure $\approx 2.2 \mathrm{MPa}$ ); after that, it decreases.

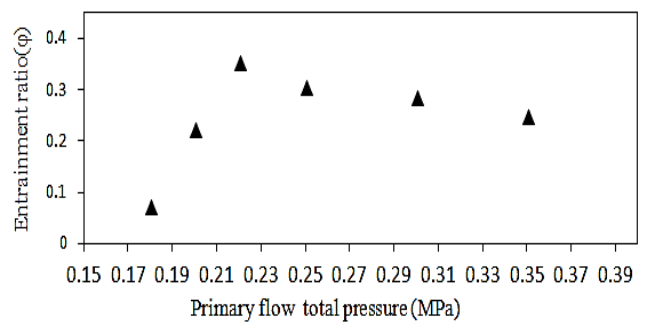

Fig. 10. Primary flow total pressure effect on entrainment ratio $(\varphi)$.

The physical phenomena associated with this pattern can also be elaborated using Mach number contours, as shown in Fig.11. The increase in primary flow total pressure shifts the secondary shock position towards downstream, resulting in the pressure inside the suction chamber increasing for the same exit pressure. The decrease in pressure difference inside the suction chamber with an increase in primary flow pressure (beyond on-design) decreases the tendency to entrain secondary flow. Due to a decrease in an effective area between the nozzle and suction chamber, the ejector can be functional at higher critical pressure. As a result, there is a decrease in the entrainment ratio.

\subsection{Effect of secondary flow pressure}

The variation in entrainment ratio with secondary flow total pressures is depicted in Fig. 12. 


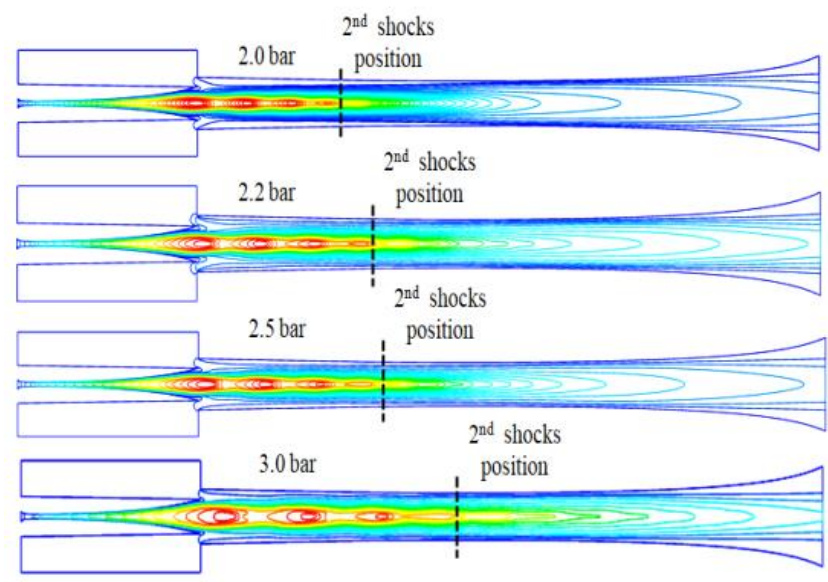

Fig. 11. Primary flow pressure effect on secondary shock position.

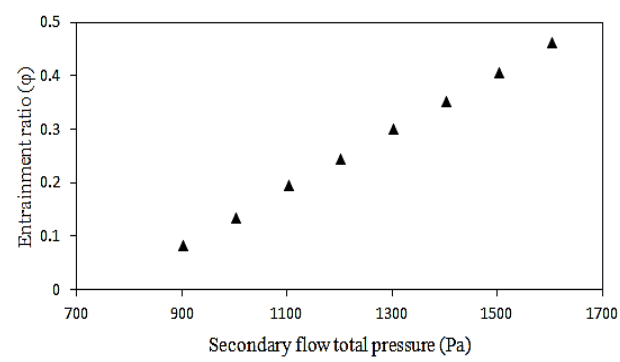

Fig. 12. Secondary flow total pressure effect on entrainment ratio $(\varphi)$.

The influence of secondary flow pressure was studied at fixed on-design primary and exit pressure.

The result illustrates an increase in entrainment ratio with the increases of secondary flow pressure. At lower secondary flow pressure, the expansion wave of the primary jet exiting the nozzle increases in width and shrink the secondary flow convergence area; as a result, a decrease in entrainment ratio. At the higher secondary flow pressure, the expansion angle of the primary jet reduces, which means allowing more space for secondary flow to entrain. It has also been observed that the increase in secondary flow pressure increases the differential of suction pressure because of an increase in entrainment ratio.

\subsection{Effect of exit pressure}

The variation in the entrainment ratio with exit pressure is shown in Fig. 13. This numerical study has been performed at a zero nozzle exit position.

The performance curve of the ejector is divided into three categories, chocked, unchoked, and reverse flow. With an increase in exit pressure, the oblique shock gets stronger, and shock waves move upstream. In this case, both primary and secondary flow gets disturbed. With further increase in exit pressure, the shock waves get stronger and prevent the secondary flow to entrain, causes a decrease in entrainment ratio. In this study, the ejector operating

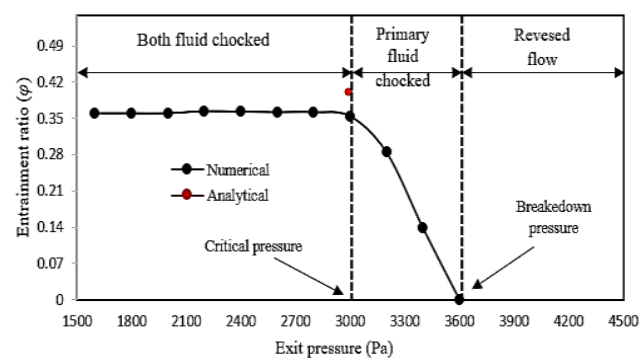

Fig. 13. Exit pressure effect on entrainment ratio $(\varphi)$.

under double fluid choking up to $3000 \mathrm{~Pa}$ in which the variation entrainment ratios are minimal. Under primary fluid alone chocked region (from $3000 \mathrm{~Pa}$ to $3600 \mathrm{~Pa}$ ), the entrainment ratio of the system drastically drops. The breakdown point for the system is $3600 \mathrm{~Pa}$.

In reverse flow, both (primary and secondary) flow does not choke, and primary flow is forced into the suction chamber. The results illustrate that to achieve maximum entrainment ratio, and the ejector must be operated within a chocked flow region, separated by critical pressure.

The effect of exit pressure on the shock position of the ejector is depicted in the Mach number contour (refer Fig. 14). From the Mach number contour of the ejector, it is noticed that with the increases of exit pressure, the distance of the second series oblique shock wave position decreases and affects the mixing phenomenon inside the entrainment region. Further, with the increase in exit pressure up to the on-design ( $\mathrm{Pe}=0.003 \mathrm{bar})$ condition, the entrainment ratio is unaltered. While increasing the exit pressure beyond on-design, the entrainment ratio decreases. In the present study, which is completely based on CRMC theory, the critical exit pressure was identified as an on-design analytical study. The numerical study shows that the analytical on-design condition of exit pressure, ejector operates with double choked (primary and secondary flow), which is also the 


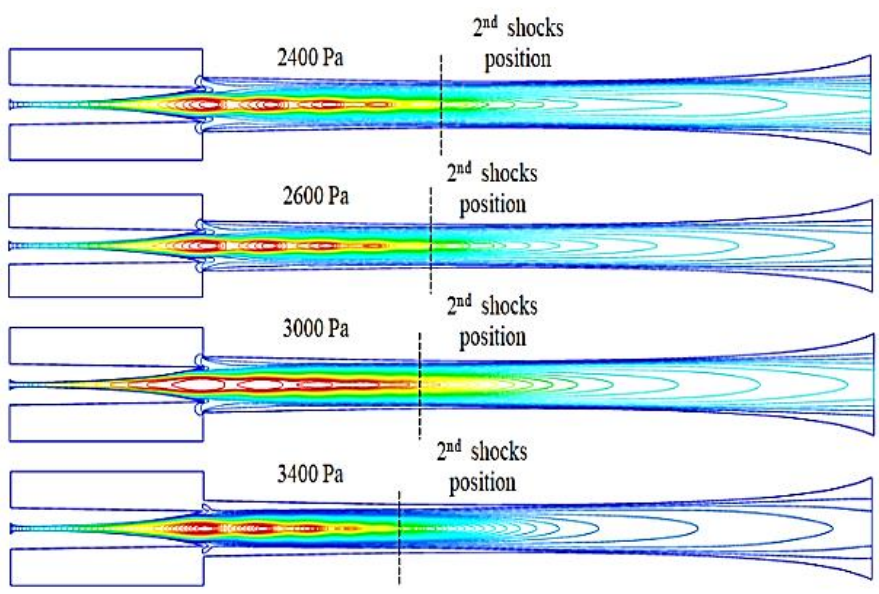

Fig. 14. Exit pressure effect on secondary shock position.

desired condition for better ejector performance [refer Fig. 13].

\subsection{Effect of different working fluids}

For this study, the computational geometry, which was designed for water-vapor, is used to analyze the influence of working fluids on the entrainment ratio. The operating condition for numerical analysis was kept to remain the same as on-design for water vapor. The entrainment ratio for various working fluids is presented in Table 4, including on-design working fluid (water-vapor). In comparison with the ondesign condition, the results show that the minimum $\%$ of deviation in entrainment is for $\mathrm{CO}_{2}$, while the maximum for $\mathrm{N}_{2}$. The variations in entrainment ratio are due to its dependency on the design, operating parameters, and working fluids. The expected deviations in analytical and numerical results of the entrainment ratio are also due to several assumptions made to develop an analytical model to compute the geometry of the ejector.

Table 4 Working fluids effect on entrainment ratio.

\begin{tabular}{|l|c|c|c|}
\hline \multirow{2}{*}{$\begin{array}{l}\text { Working } \\
\text { fluids }\end{array}$} & \multicolumn{2}{|c|}{ Entrainment ratio $(\varphi)$} & $\begin{array}{c}\% \\
\text { deviations }\end{array}$ \\
\cline { 2 - 3 } $\begin{array}{l}\text { Water- } \\
\text { Vapour }\end{array}$ & 0.354 & $0.40^{\#}$ & 11.50 \\
\hline Air & 0.320 & -- & 20.00 \\
\hline $\mathrm{N}_{2}$ & 0.310 & -- & 22.50 \\
\hline $\mathrm{CO}_{2}$ & 0.360 & -- & 10.00 \\
\hline
\end{tabular}

${ }^{\#}$ on-design

\section{CONCLusion}

In the current work, the constant rate of momentum change (CRMC) theory for real gas is proposed and employed to compute ejector geometry. The results obtained through the analytical model are validated with the numerical study at the same on-design operating condition. Furthermore, the effects of various operating pressures, along with working fluids on ejector entrainment, were also discussed. The major conclusions of the work can be summarized as below:

The flow characteristics inside the ejector play a vital role in spotting the effective area in the mixing zone, oblique shock waves in the diffuser section, and developing a high-performance ejector.

The numerical predicted Mach number and pressure variation qualitatively match with on-design analytical results.

The entrainment ratio of the ejector increases with the increase of secondary flow pressure and primary flow pressures (within the on-design condition)

The entrainment ratio of the ejector decreases with the increase of exit pressure and primary flow pressure (beyond on-design condition).

With an increase in primary flow pressure, the $2^{\text {nd }}$ shock position shifts downstream and upstream, increasing exit pressures.

The percentage of deviation in terms of numerical entrainment ratio is $11.50 \%$ with the analytical on-design condition.

The numerically identified critical back pressure is the same as the analytical on-design exit pressure.

The entrainment ratio varies with variation working fluids for designed ejector geometry for watervapour. The maximum entrainment ratio is achieved for $\mathrm{CO}_{2}$ compared to other working fluids viz, Air, $\mathrm{N}_{2}$, and Water-vapour.

\section{APPENDIX A}

Calculation of thermodynamic properties at the end of mixing/ inlet diffuser (Eames 2002).

The design of the mixing section is a critical step in the development of a supersonic ejector, as it generates maximum entropy during the intense 
interaction of supersonic primary and subsonic secondary fluid flows. As shown in Fig. 2, at section $\left(I-I^{\prime}\right)$, the primary and secondary flow enters with different thermodynamics properties. At the section $\left(J-J^{\prime}\right)$, the flow must reach thermodynamic equilibrium. All the required properties to compute the mixing and diffuser profile and flow properties are calculated based on constant static pressure mixing $(\delta P=0)$.

The entrainment process of primary and secondary flow may be modeled as follows.

$$
\sum F=\oint \Omega \delta P=m_{p}(1+\varphi) C_{j-j^{\prime}}-m_{p} C_{n, e}-m_{s} C_{s}
$$

The mixed fluid velocity at section $J-J^{\prime}$.

$$
C_{J-J^{\prime}}=\frac{C_{n, e}+\varphi C_{S}}{1+\varphi}
$$

The mixed fluid total temperature at section $J-J^{\prime}$.

$$
T_{o, J-J^{\prime}}=\frac{T_{o, p}+\varphi T_{o, S}}{1+\varphi}
$$

The mixed fluid static temperature at section $J-J^{\prime}$.

$$
T_{J-J^{\prime}}=T_{o, J-J^{\prime}}-\frac{c_{J-J^{\prime}}^{2}}{2 c_{p}}
$$

The mixed fluid static pressure at section $J-J^{\prime}$.

$P_{J-J^{\prime}}=P_{o, S}-\frac{\rho_{s} C_{s}^{2}}{2} \approx P_{n, e}$

The mixed fluid total pressure at section $J-J^{\prime}$.

$$
P_{o, J-J^{\prime}}=P_{J-J^{\prime}}\left(\frac{T_{o, J-J^{\prime}}}{T_{J-J^{\prime}}}\right)^{(\gamma /(\gamma-1))}
$$

The Exit Mach Number at section $J-J^{\prime}$.

$$
M_{J-J^{\prime}}=\frac{C_{J-J^{\prime}}}{\sqrt{\gamma R T_{J-J^{\prime}}}}
$$

The exit diameter at section $J-J^{\prime}$. can be calculated using the continuity equation.

$$
D_{J-J^{\prime}}=\sqrt[2]{\frac{m_{p}(1+\varphi) R T_{J-J^{\prime}}}{\pi P_{J-J^{\prime}} C_{J-J^{\prime}}}}
$$

The Friction Losses as local Fanning friction factor for ejector geometry can be calculated as given below.

$$
f_{J-J^{\prime}}=\frac{0.0625}{\left[\log _{10}\left(\frac{K}{3.7 D_{J-J^{\prime}}}+\frac{5.74}{R_{e J-J^{\prime}}^{0.9}}\right)\right]^{2}}
$$

Where;
Reynolds number

$$
R_{e J-J^{\prime}}=\frac{\rho_{J-J^{\prime}} C_{J-J^{\prime}} D_{J-J^{\prime}}}{\mu_{J-J^{\prime}}}
$$

Sutherland equation for dynamic viscosity

$$
\begin{aligned}
& \mu_{J-J^{\prime}}=\frac{\propto_{1} T_{J-J^{\prime}}^{1.5}}{T_{J-J^{\prime}}+\propto_{2}} \\
& \propto_{1}=1.703^{*} 10^{-5} \mathrm{~kg} \mathrm{~m}^{-1} K^{-1} \text { and } \\
& \propto_{2}=416.67 \mathrm{~K} \text { for water vapour. }
\end{aligned}
$$

\section{REFERENCES}

Ariafar, K., D. Buttsworth, G. Al-doori and N. Shari (2016) Mixing layer effects on the entrainment ratio in steam ejectors through ideal gas computational simulations. Energy 95, 380-92.

Aidoun, Z. and M. Ouzzane (2004) The effect of operating conditions on the performance of a supersonic ejector for refrigeration Impact. International Journal of Refrigeration 27, 974 84.

Croquer, S., S. Poncet and Z. Aidoun (2017) Thermodynamic modelling of supersonic gas ejector with droplets. Entropy 19, 579.

Cardemil, J. M. and S. Colle (2012) A general model for evaluation of vapor ejectors performance for application in refrigeration. Energy Conversion and Management 64, 79-86.

Eames, I.W. (2002) A new prescription for the design of supersonic jet-pumps: the constant rate of momentum change method. Applied Thermal Engineering 22, 121-131.

Gagan, J., K. Smierciew, D. Butrymowicz and J. Karwacki (2014) Comparative study of turbulence models in application to gas ejectors. International Journal of Thermal Sciences 78, 9-15.

Huang, B. J., C.B. Jiang and F. L. Hu, (1985) Ejector performance characteristics and design analysis of jet refrigeration system. Journal of Engineering for Gas Turbines and Power 107, 792-802.

Keenan, J. and E. Neumann (1942) A simple air ejector. ASME Journal of Applied Mechanics. 64,75-82.

Kumar, V., P. M. V. Subbarao and G. Singhal (2019) Effect of nozzle exit position (NXP) on variable area mixing ejector. SN Applied Sciences 1,1-9.

Kumar, V., G. Singhal and P. M. V. Subbarao (2018) Realization of novel constant rate of kinetic energy change (CRKEC) supersonic ejector. Energy 164, 694-706.

Kumar, V., G. Singhal and P. M. V. Subbarao (2013) Study of supersonic flow in a constant rate of momentum change (CRMC) ejector with 
S. K. Yadav al. / JAFM, Vol. 14, No. 6, pp. 1705-1716, 2021.

frictional effects. Applied Thermal Engineering $60,61-71$.

Li, Y., J. Deng and L. Ma (2019) Experimental study on the primary flow expansion characteristics in transcritical $\mathrm{CO} 2$ two-phase ejectors with different primary nozzle diverging angles. Energy 186.

Lin, C., W. Cai, Y. Li, J. Yan, Y. Hu and K. Giridharan (2013) Numerical investigation of geometry parameters for pressure recovery of an adjustable ejector in multi-evaporator refrigeration system. Applied Thermal Engineering 61,649-656.

Ramesh, A. S. and S. J. Sekhar (2017) Analytical and numerical studies of a steam ejector on the effect of nozzle exit position and suction chamber angle to fluid flow and system performance. Journal of Applied Fluid Mechanics 10 (1), 369-378.

Ruangtrakoon, N., T. Thongtip, S. Aphornratana and T. Sriveerakul (2013) CFD simulation on the effect of primary nozzle geometries for a steam ejector in refrigeration cycle. International Journal of Thermal Sciences 63, 133-45.

Su, L. and R. K. Agarwal (2016) CFD simulation of a supersonic steam ejector for refrigeration application. American Society of Mechanical Engineering. Fluids Engineering Division Summer meeting. FEDSM, V01AT03A006, 2015-2018.

Shestopalov, K. O., B. J. Huang, V. O. Petrenko and O. S. Volovyk (2015) Investigation of an experimental ejector refrigeration machine operating with refrigerant $\mathrm{R} 245 \mathrm{fa}$ at design and off-design working conditions. Part 1 . Theoretical analysis. International Journal of Refrigeration 55, 201-211.

Seehanam, W., K. Pianthong, M. Behnia, K. Chunnanond and S. Aphornratana (2007) Simulation on performance of CPM and CRMC Steam Ejectors Using CFD Technique. 18th Annu Conf Mech Eng Netw Thail.2-6.

Vereda, C., R. Ventas, A. Lecuona and M. Venegas (2012) Study of an ejector-absorption refrigeration cycle with an adaptable ejector nozzle for different working conditions. Applied Energy 97, 305-312.

Wu, Y., H. Zhao, C. Zhang, L. Wang and J. Han (2018) Optimization analysis of structure parameters of steam ejector based on CFD and orthogonal test. Energy 151, 79-93.

Yadav, S. K., V. Kumar, K. M. Pandey and R. Gupta (2020) Development of the constant rate of momentum change (CRMC) variable area nozzle, Mater. Today Proc.

Zhu, Y. and P. Jiang (2014) Experimental and numerical investigation of the effect of shock wave characteristics on the ejector performance. International Journal of Refrigeration 40, 31-42.

Zhu, Y., W. Cai, C. Wen and Y. Li (2009) Numerical investigation of geometry parameters for design of high-performance ejectors. Applied Thermal Engineering 29, 898-905. 